\title{
TIPOLOGÍAS DE ERRORES EN LA EXPRESIÓN ESCRITA
}

\author{
CRISTINA RODRÍGUEZ GARCÍA
}

Universidad Masaryk de Brno, República Checa

\begin{abstract}
Resumen. El objetivo de esta comunicación es presentar los distintos criterios que se pueden seguir para establecer una tipología de errores en la expresión escrita de aprendices de ELE (español como lengua extranjera). Esta variedad de criterios (Vázquez, 1999) permitirá orientar la investigación hacia un tratamiento más preciso de las idiosincrasias que presenta la interlengua escrita. Para ello, la metodología seguida se apoyará en la corriente del Análisis de Errores (Corder, 1967) dentro del marco de la adquisición de segundas lenguas, en el ámbito de la Lingüística Aplicada. A partir de un corpus de muestras de expresión escrita, elaboradas por estudiantes universitarios checos y eslovacos, se analizarán los posibles escollos que puedan surgir en el tratamiento de los errores. El análisis se centrará en los errores morfosintácticos de los textos y en la aplicación de una taxonomía de criterio lingüístico para su corrección. Se comprobará que algunos errores se pueden clasificar en más de una categoría o que, en ocasiones, el investigador deberá adaptar la taxonomía a las idiosincrasias que encuentre, ya que es posible que la tipología no presente la categoría necesaria para un tipo de error concreto. Las conclusiones del estudio revelarán cuáles son las ventajas y las desventajas de aplicar este método en el tratamiento de los errores gramaticales y permitirán reflexionar sobre los aspectos didácticos de la corrección de errores.
\end{abstract}

Palabras clave: análisis de errores, corrección, español como lengua extranjera, expresión escrita, interlengua, tipología de errores

\section{INTRODUCCIÓN}

El tratamiento de los errores en las clases de ELE es una de las cuestiones más discutidas en la bibliografía especializada en didáctica de lenguas extranjeras (Fernández, 1997; Vázquez, 1999; Ribas Moliné y d’Aquino Hilt, 2004, Rodríguez García, 2013; Montoro Cano, 2014). La preocupación por el tratamiento de las idiosincrasias se refleja en algunos modelos de análisis de datos surgidos dentro de la Lingüística Aplicada, como la corriente del Análisis de Errores (Corder, 1967).

Esta corriente de investigación apareció a finales de los años 60 y se desarrolló a lo largo de los años 70 del siglo XX. En un principio, surgió como reacción a la corriente anterior de los años 50 y 60, conocida como Análisis Contrastivo, 
cuyo objetivo era evitar los errores en el aprendizaje de una lengua extranjera a partir del contraste de la lengua materna de los aprendices con la lengua meta. Sin embargo, tal modelo no consiguió que los errores desaparecieran completamente debido, entre otros motivos, al carácter inherente de las idiosincrasias en cualquier proceso de aprendizaje. Así, este fue el contexto para que se abriera un nuevo camino en el tratamiento de las producciones idiosincráticas con el Análisis de Errores, centrado en descubrir las causas de los errores y las estrategias de aprendizaje subyacentes en la actuación lingüística de los estudiantes.

El punto de partida para este cambio de paradigma se encuentra en la publicación en 1967 del artículo de Corder The Significance of Learners' Errors, un trabajo que recogía la importancia de estudiar las producciones reales de los estudiantes para establecer qué errores estaban causados por interferencias de la lengua materna y cuáles estaban causados por otras razones. Este modelo proponía una serie de pasos para tratar las idiosincrasias que se dan en la práctica docente y que son habituales en las clases de idiomas. Tales pasos se resumen en: identificación del error, clasificación a partir de una tipología, descripción, explicación y evaluación de su gravedad desde el punto de vista comunicativo. Entonces, a diferencia del Análisis Contrastivo, que llevaba a cabo un trabajo a priori de contraste entre lenguas para arrojar sus predicciones en cuanto al comportamiento lingüístico de los aprendices, el Análisis de Errores proponía un trabajo a posteriori con las muestras de lengua reales de los estudiantes. De hecho, algunos años después Corder (1972) reconsideró las premisas del Análisis de Errores y amplió su campo a la globalidad de las producciones de los estudiantes; es decir, el análisis no solo se centraba en los errores, sino también en aquellas estructuras que fueran correctas desde el punto de vista normativo y del uso de la lengua.

Por lo tanto, el Análisis de Errores es el paradigma metodológico seguido en el tratamiento de las idiosincrasias que se presentan en esta comunicación. Para poner en práctica esta metodología se analizan los errores morfosintácticos que cometen un grupo de estudiantes universitarios de español, checos y eslovacos, a través de un corpus de 393 muestras de expresión escrita. Estos textos se han entregado a lo largo de los estudios de Grado de Lengua y Literatura españolas durante los cursos 2014-2017 y pertenecen a una asignatura obligatoria, Jazykový seminár I-VI (Seminario de lengua I-VI), que debe cursarse los seis semestres de la carrera. El objetivo final del análisis es clasificar los errores presentes a partir de una tipología que siga unos criterios concretos.

\section{CRITERIOS PARA CLASIFICAR ERRORES}

El problema de investigación que se presenta es la variedad de criterios existentes a la hora de establecer una tipología de idiosincrasias según el Análisis de Errores. De ahí, la necesidad de elegir un criterio que sirva de base, que a su vez podría complementarse con otros elementos, para proceder con la clasificación de los 
errores. Desde los años 70 hasta la actualidad han aparecido distintos trabajos especializados en los criterios clasificatorios de los errores en una lengua extranjera; basta echar un vistazo a referencias como Corder (1972), Bantas (1980), Dulay et al. (1982), Fernández (1997), Vázquez (1999) o Santos Gargallo (2004) para comprobarlo. Por ello, la tarea del investigador o del docente consistirá en elegir el criterio más adecuado para tratar los errores en el aula. Así, en este artículo la atención se centra en cuatro criterios distintos, pero a la vez complementarios: el estratégico, el etiológico, el lingüístico y el comunicativo.

Con el criterio estratégico se clasifican los errores a partir de las estrategias que emplean los aprendices; es decir, a partir del mecanismo psicolingüístico que subyace en las producciones idiosincrásicas. Las estrategias que se reconocen son muy variadas: la omisión, la adición, la yuxtaposición, la falsa colocación y la falsa selección. A continuación, se ofrecen algunos ejemplos ilustrativos sacados del corpus de muestras. Entre paréntesis se indica si se trata de un aprendiz checo (C) o eslovaco (E) y se incluye el código de la redacción. Además, se han marcado los errores con un asterisco y cursiva, y se han añadido las posibles correcciones:

(E1) ... cada ${ }^{*}$ __ requiere cierto tiempo (una).

En el ejemplo se reconoce un error por omisión del cardinal que acompaña al determinativo distributivo, una dificultad muy común en aprendices checos (Rodríguez García, 2013) y eslovacos (Montoro Cano, 2014), aunque también de otras lenguas eslavas, como el polaco (Fernández Jódar, 2007).

$(\mathrm{C} 26)^{*}$ En este fin de semana (X).

En el ejemplo se detecta un error por adición innecesaria de la preposición 'en', como reflejo de las dificultades causadas por los valores propios de esta clase de palabra (Rodríguez García, 2016).

(E78) ... una manera ${ }^{*}$ __ tiene su significado (que).

Aquí se comprueba un error por yuxtaposición de dos elementos al no tener en cuenta los nexos requeridos por la sintaxis.

(C77) ... donde * se también encuentra... (se encuentra también/ también se encuentra).

Esta es una muestra de error por colocación de un elemento en un orden sintagmático incorrecto, ya que, por influencia de la lengua materna, se adjudica la segunda posición lógica al pronombre 'se' en el sintagma.

(C2) ... poder estudiarlo ${ }^{*}$ solamente (sola $=$ de forma autodidacta).

El último ejemplo aportado para ilustrar el criterio estratégico es un error por falsa selección a causa de la adverbialización del adjetivo. Para poder expresar que el aprendiz estudia de forma autodidacta, de manera errónea elige el adverbio 'solamente' expresando un significado de unicidad frente al autodidactismo del adjetivo 'sola', en este caso. 
Otro criterio posible es el criterio etiológico, que divide los errores en dos grandes grupos: errores interlinguales y errores intralinguales. Para diferenciarlos, hay que atender al origen de las idiosincrasias. Por un lado, los errores interlinguales son aquellos causados por interferencias de la lengua materna de los aprendices, $o$ bien, por influencia de otras lenguas extranjeras. Como ejemplo:

(E102) ... para ir a la *ordinación del médico (consulta).

Según este criterio, el problema detectado podría clasificarse como error interlingual. En esta oración se encuentra el uso de una palabra que no existe en español, pero cuya formación se ha llevado a cabo siguiendo unas reglas morfológicas congruentes. Además, se trata de un préstamo del eslovaco, de la palabra ordinácia, que equivale a la consulta del médico en español.

Por otro lado, los errores intralinguales son los que resultan de un conflicto interno de las reglas de la L2; es decir, de las hipótesis de aprendizaje que realiza el aprendiz en español. Una muestra:

(C68) ... *varios fuentes (varias).

Aquí se detecta un error intralingual causado, posiblemente, por la arbitrariedad del sistema patente en algunos errores de reconocimiento del género. Casos como 'la fuente' vs. 'el puente' pueden despistar al aprendiz.

Si bien, este criterio ofrece una distinción muy clara en la teoría, en la práctica, cuando se analizan y trabajan los errores de los aprendices, se encuentran algunos puntos débiles en su aplicación, tal y como apunta Vázquez (1999: 34), ya que es posible que el investigador no siempre llegue a distinguirlos. De hecho, en el caso concreto de *varios fuentes, también se podría interpretar como un error interlingual si se tiene en cuenta que la palabra 'fuente' en checo, $z d r o j$, es de género masculino.

El siguiente criterio es el lingüístico y propone una clasificación de los errores a partir de las categorías afectadas y los subsistemas de la lengua, que pueden ser el fonético-fonológico-ortográfico, el morfosintáctico, el léxico-semántico, el pragmático o el discursivo. Algunos ejemplos:

(E111) ... en la *república Checa (República).

En este caso se reconoce un error ortográfico por uso de minúscula en el nombre del país.

(E146) ${ }^{*}$ Me recuerdo este momento (Recuerdo/Me acuerdo de).

Aquí aparece un error gramatical por cruce con la estructura 'acordarse de', puesto que las restricciones sintácticas de estos verbos no permiten un uso pronominal del verbo 'recordar'.

(C38) En el liceo *me siempre ayudó con *la matemática (siempre me ayudó/las matemáticas). 
El ejemplo muestra un error gramatical que afecta al orden de la estructura por la posición del pronombre, de nuevo en la segunda posición lógica, tal y como se ha señalado en el cuarto ejemplo para ilustrar el criterio estratégico. Además, hay que añadir un error léxico de número como rasgo inherente del sustantivo, con el uso de 'matemática' en singular.

El último criterio presentado es el comunicativo, un criterio que clasifica los errores según el grado de distorsión, dificultad o distracción que puedan causar. Así, este criterio distingue entre errores irritantes para el receptor, estigmatizantes para el emisor, cómicos o de ambigüedad. Algunas muestras, esta vez extraídas de ejemplos de producción oral en las clases, son:

(C Producción oral) En Karviná había mucha producción de *abrón (carbón).

Con este ejemplo se ilustra el impacto que puede causar este tipo de errores desde el punto de vista comunicativo. Si el error presentado estuviera extraído de un texto escrito, podría justificarse como una errata propia de una escritura rápida y una falta de revisión; algo que, por otro lado, también podría ocurrirle a un hablante nativo. Sin embargo, al tratarse de producción oral, un error de estas características puede resultar estigmatizante para el emisor.

(E Producción oral) He barrido el comedor con la *escopeta (escoba).

Otro ejemplo de error que, clasificado desde el punto de vista de la comunicación, puede resultar cómico para el receptor.

Entonces, una vez presentados los principales criterios para clasificar los errores en la expresión escrita, se comprueba que cada uno categoriza e interpreta las idiosincrasias desde su propia dimensión. Por ello, el investigador o el profesor deberá decidir cuál o cuáles de ellos seguirá para establecer una tipología de errores que se ajuste a los objetivos de su trabajo.

\section{APLICACIÓN DE LA TIPOLOGÍA A ERRORES MORFOSINTÁCTICOS}

En este apartado la propuesta consiste en establecer una tipología que se ajuste al objetivo planteado en la introducción: conseguir una visión clara de las dificultades morfosintácticas en las muestras de expresión escrita de aprendices extranjeros de español. Por esta razón, se opta por una tipología mixta con un criterio de base, en este caso el lingüístico, teniendo en cuenta, a la vez, elementos complementarios de otros criterios, como el estratégico y el comunicativo. De esta forma, se obtendrá una visión clara de cuáles son las dificultades que afectan a las siguientes categorías: paradigmas, concordancias, artículos, determinantes, pronombres, verbos, preposiciones, estructura de la oración y relación entre oraciones. 
Una vez formulada la tipología, se pasa a ejemplificar su aplicación a algunos errores morfosintácticos encontrados en las redacciones analizadas. El trabajo realizado hasta la fecha muestra tres posibles situaciones a partir de su aplicación:

La primera situación es aquella en la que los errores encajan sin problemas en alguna de las categorías de la tipología. Por ejemplo:

(C79) ... de color botella *verde (verde botella).

A partir de la tipología propuesta, se puede clasificar este error gramatical como un fallo que afecta al orden en la estructura de la oración.

(C129) ... porque no corren, no se *muevan (mueven).

Este otro ejemplo muestra un error gramatical por una equivocación en la elección del modo verbal, ya que la oración requiere el uso del indicativo, en lugar del subjuntivo.

La segunda situación, que ocurre con relativa frecuencia, es aquella en la que los errores se pueden clasificar en más de una categoría. Dos muestras:

(E26) *___He ${ }^{*}$ escrito ${ }^{*}$ con mis amigos en una red social.

Por un lado, se puede interpretar este error gramatical a partir de la elección de la preposición 'con' por 'a', puesto que en español es 'escribir a alguien' ( $\mathrm{He}$ escrito a). Por otro lado, también es posible clasificar este error por la omisión del pronombre, ya que 'escribirse con alguien' sí es correcto (Me he escrito). Sin embargo, también se podría etiquetar este error como un problema léxico por el uso de lexemas con semas comunes pero no intercambiables en el mismo contexto. A pesar de las similitudes, no es lo mismo 'chatear' que 'escribir' (He chateado). Así, con un mismo error se encuentra más de una posibilidad clasificatoria.

(E75) ... panoramas *bonitas gracias a *las que ven.

En este ejemplo se ve un error gramatical por concordancia de género errónea (bonitos/los), aunque también podría interpretarse como un error léxico de reconocimiento de género. En función de la etapa de la interlengua en la que se encuentre el aprendiz, este puede interpretar 'panoramas' como una palabra de género femenino y por eso establece una concordancia errónea.

La tercera situación es aquella en la que determinados errores no se ajustan a ninguna de las categorías propuestas, por lo que se deberá adaptar la tipología. Por ejemplo:

(C114) *Dentro de una semana permitieron *irme.

Este caso contiene un error gramatical por la elección de una locución adverbial que expresa un plazo futuro, así que debería cambiarse por otra adecuada al tiempo de pasado (Al cabo de). Como la tipología no presenta ninguna categoría que pueda recoger este tipo de errores, se propone añadir una nueva categoría que englobe aquellos errores que afecten a adverbios y a 
locuciones adverbiales. Además, en este ejemplo se encuentra un error gramatical que no presenta problemas clasificatorios, causado por el uso de un infinitivo en lugar de una oración subordinada con subjuntivo (permitieron que me fuera).

(C107) ... porque * ya cuatro días me duele.

Este caso supone un error por el calco de la estructura checa $u z ̌$ ('ya' en español) + presente para indicar la duración de una actividad, en lugar de 'hace $\mathrm{X}$ tiempo + que' (hace cuatro días que me duele). Como se trata de un error de estructura, categoría que sí aparece en la tipología, se propone añadir una subcategoría dentro de la estructura para aquellos errores por calcos de tipo sintáctico; es decir, cuando el estudiante traslada al español la misma estructura sintáctica que utiliza en su lengua materna.

\section{CONCLUSIONES}

Las conclusiones obtenidas a partir de la aplicación de la tipología propuesta a los errores morfosintácticos permiten comentar brevemente algunas ventajas y desventajas.

Como puntos más desfavorables, se alude a la posible falta de unanimidad entre los profesores para clasificar determinados errores, tal y como se comprueba con algunos ejemplos. Este hecho podría derivar en una cierta subjetividad, algo que ya han apuntado otros investigadores (Fernández, 1997: 44). Asimismo, desde el punto de vista didáctico, esta clasificación de los errores sería provechosa en determinados contextos de enseñanza, pero no en todos. Si los aprendices están acostumbrados a trabajar con la lengua desde una vertiente metalingüística, como en el caso de estudiantes universitarios de Filología, Traducción o con futuros profesores, entonces este tratamiento sí puede ser viable. En cambio, en otros contextos con grupos más heterogéneos o de inmersión lingüística, tal vez no sea el enfoque más adecuado debido a que no todos los aprendices aplicarán las mismas estrategias metacognitivas ni tendrán los mismos conocimientos previos.

En cuanto a los puntos favorables, la aplicación de los criterios presentados ofrece una visión clara y precisa de los errores que cometen los aprendices. Este hecho sirve para reconocer cuáles son las áreas de más dificultad en el aprendizaje, con lo que será posible adaptar los contenidos de las asignaturas, así como preparar actividades específicas para aclarar y mejorar los aspectos más problemáticos. También, desde el punto de vista lingüístico, este tipo de análisis permite obtener una descripción de la interlengua de los aprendices, ya que no solo se tienen en cuenta los errores, sino también aquellas producciones correctas de la lengua. La interlengua refleja todas las etapas por las que pasa el aprendizaje y aquí también se incluyen las estrategias que muestran los errores analizados. Además, como se ha comprobado, la tipología propuesta es un sistema flexible que permite las adaptaciones que sean necesarias.

En conclusión, los distintos criterios existentes para clasificar los errores pueden ayudar a perfilar el objetivo del tratamiento de las idiosincrasias. Si el 
interés se centra más en trabajar en clase las categorías lingüísticas, el criterio a tener en cuenta deberá ser el lingüístico; pero si se quiere realizar un análisis desde el punto de vista de la transmisión del mensaje, la necesidad de relectura o el esfuerzo interpretativo por parte del receptor, es posible contar con otros criterios para efectuar dicho análisis, como el comunicativo. Sea cual sea el criterio elegido, lo importante es que el tratamiento de las idiosincrasias y la corrección que se lleven a cabo en el aula ayuden al aprendiz a avanzar en su aprendizaje.

\section{REFERENCIAS BIBLIOGRÁFICAS}

Bantas, A. (1980) Suggestions for Classifying Errors in Foreign Language Acquisition. Revue Roumaine de Linguistique, XXV (2): 135-143.

Corder, S. P. (1967) The Significance of Learner's Errors. IRAL, (5): 161-170.

Corder, S. P. ([1972]1981) The Role of Interpretation in the Study of Learners' Errors. Error Analysis and Interlanguage (pp. 35-44). London: Oxford University Press.

Dulay, H., Burt M. y Krashen S. (1982) Language Two. New York and Oxford: Oxford University Press.

Fernández, S. (1997) Interlengua y análisis de errores en el aprendizaje del español como lengua extranjera. Madrid: Edelsa.

Fernández Jórdar, R. (2007) Análisis de errores léxicos, morfosintácticos y gráficos en la lengua escrita de los aprendices polacos de español. Tesis doctoral. Universidad Adam Mickiewicz. Biblioteca Virtual redELE (4). Disponible en https://www.educacionyfp.gob.es/dam/jcr:1709ed7be843-4f54-9413-237adb00b8f9/2007-bv-08-10raulfernandez-pdf.pdf [Consultado el 10 de marzo de 2019].

Montoro Cano E. R. (2014). La enseñanza del español como lengua extranjera en Eslovaquia (Bratislava): historia y actualidad. Tesis doctoral. Granada: Universidad de Granada.

Ribas Moliné, R. y d’Aquino Hilt, A. (2004) ¿Cómo corregir errores y no equivocarse en el intento? Madrid: Edelsa.

Rodríguez García, C. (2013) La enseñanza del español en la República Checa. Problemas específicos. Revista redELE: Revista electrónica de didáctica del español lengua extranjera (25). Madrid: Ministerio de Educación, Cultura y Deporte. Disponible en https://www. educacionyfp.gob.es/dam/jcr:cd0fed92-89e1-4d34-a7e4-81e4f844a5e6/2013-redele-2501 cristina-rodr-guez-pdf.pdf [Consultado el 20 de marzo de 2019].

Rodríguez García, C. (2016) El uso de las preposiciones en la producción escrita de estudiantes de ELE. Valores generales y análisis de errores. En D. Poláková y D. Kratochvílová. (eds.) Actas del congreso "Las palabras (des)atadas" Encuentro de hispanistas 2015 (pp. 68-79). Alicante: Biblioteca Virtual Miguel de Cervantes. Disponible en http://www.cervantesvirtual. com/obra/actas-del-congreso-las-palabras-desatadas-encuentro-de-hispanistas-2015/ [Consultado el 10 de marzo de 2019].

Santos Gargallo, I. (2004) El análisis de errores en la interlengua del hablante no nativo. En J. Sánchez Lobato (2004) Vademécum para la formación de profesores. Enseñar español como segunda lengua (L2) / lengua extranjera (LE) (pp. 391-410). Madrid: S.A. Sociedad General Española de Librería.

Vázquez, G. (1999) ¿Errores? ¡Sin falta! Madrid: Edelsa. 


\section{TYPOLOGY OF ERRORS IN WRITTEN SPANISH}

Abstract. The aim of this paper is to present the variety of criteria that can be followed to classify mistakes in written Spanish. This variety (Vázquez, 1999) will allow us to establish a typology of errors in order to orient our investigation towards more precise correction during our lessons. In order to achieve this goal, we will follow the methodology of Error Analysis (Corder, 1967) within the Acquisition of Second Languages and Applied Linguistics. At the same time, we will analyze a corpus of essays written by Czech and Slovak college students to show to what extent a specific typology of errors is suitable to correct them. In particular, we will apply this typology to morphosyntactic errors to find out three different scenarios: some mistakes can be classified into one category; some mistakes can be classified into more than one category simultaneously; and some other mistakes will not fit into any category, so they will need an adaptation of the typology. The conclusions of our investigation will reveal the advantages and disadvantages of applying this method of marking and will lead us to discuss the different ways of error correction.

Key words: Error Analysis, correction, Spanish as a Foreign Language, writing, interlanguage, error typology

Cristina Rodríguez García (Mgr.) trabaja actualmente en la Universidad Masaryk de Brno, República Checa. Sus intereses académicos incluyen la Lingüística Aplicada, el análisis de errores y la enseñanza de español y de catalán como lenguas extranjeras. Correo electrónico: crissrogar@gmail.com 